\title{
Platelet activity measured by a rapid turnaround assay identifies coronary artery bypass grafting patients at increased risk for bleeding and transfusion complications after clopidogrel administration
}

\author{
Todd K. Rosengart, MD, ${ }^{\text {a,b }}$ Jamie L. Romeiser, MPH, ${ }^{\mathrm{c}}$ Lauren J. White, BS, ${ }^{\mathrm{c}}$ Ashley Fratello, BA, ${ }^{\mathrm{c}}$ \\ Eleanor Fallon, BA, ${ }^{\mathrm{c}}$ Lisa Senzel, $\mathrm{MD}, \mathrm{PhD},{ }^{\mathrm{d}}$ and Annie Laurie Shroyer, $\mathrm{PhD}^{\mathrm{c}}$
}

\begin{abstract}
Background: We sought to establish a metric for easily estimating bleeding and transfusion risks for cardiac surgery patients after antiplatelet agent use.
\end{abstract}

\begin{abstract}
Methods: Deidentified records of patients who underwent coronary artery bypass grafting (CABG) at our institution (January 2010-June 2011) were searched for patients without identified risk factors for excessive bleeding who underwent documented $\mathrm{P}_{2} \mathrm{Y}_{12}$ testing after clopidogrel administration $(\mathrm{n}=276)$. Clinical outcomes were analyzed according to whether preoperative platelet function was higher (platelet reactivity units [PRUs], $\geq 237$ ) or lower (PRU, <237) and according to preoperative PRU cutoffs: high ( $>290$, or no clopidogrel), intermediate $(200-290)$, or low $(<200)$.
\end{abstract}

Results: Eighty-five patients (57\%) received allogeneic blood products at 24 hours or less postoperatively: 33 $(22 \%)$ received fresh frozen plasma, and $57(38 \%)$ received platelets. The median 12-hour chest tube output (CTO) was $350 \mathrm{~mL}$ (interquartile range, $260-490 \mathrm{~mL})$; CTO was "high" $(>437 \mathrm{~mL})$ in $62(42 \%)$ of the clopidogrel-treated patients. Lower-PRU patients were more likely to receive coagulation factors (odds ratio [OR], 2.82; $P=.0004)$ and to have high CTO or coagulation factor transfusion $(\mathrm{OR}, 2.35 ; P=.02)$ than higher-PRU patients. Likewise, intermediate- and low-PRU patients had incrementally greater incidences of high $\mathrm{CTO}(\mathrm{OR}, 1.72 ; P=.002)$ and coagulation factor transfusion $(\mathrm{OR}, 2.08 ; P<.0001)$ than high-PRU/no clopidogrel patients. High CTO or coagulation factor transfusion was more frequent in intermediate-PRU $(\mathrm{OR}, 2.67 ; P=.02)$ and low-PRU (OR, 5.08; $P=.0002)$ patients than in high-PRU/no clopidogrel patients.

Conclusions: Among clopidogrel-treated CABG patients, preoperative platelet function testing can identify those at increased risk for postoperative bleeding and transfusion. (J Thorac Cardiovasc Surg 2013;146:1259-66)

\section{Supplemental material is available online.}

Many patients who undergo open heart surgery are receiving long-term antiplatelet treatment at the time of the procedure because of recent percutaneous coronary intervention (PCI), for acute coronary syndromes, or for other reasons. ${ }^{1}$ More specifically, nearly $21 \%$ of patients who have undergone PCI subsequently undergo coronary

\footnotetext{
From the Michael E. DeBakey Department of Surgery, ${ }^{\text {a }}$ Baylor College of Medicine, Houston, Tex; the Department of Cardiovascular Surgery, ${ }^{\mathrm{b}}$ Texas Heart Institute at St Luke's Episcopal Hospital, Houston, Tex; and the Departments of Surgery, ${ }^{\mathrm{c}}$ and Pathology, ${ }^{\mathrm{d}}$ Stony Brook University Medical Center, Stony Brook, NY.

Disclosures: Authors have nothing to disclose with regard to commercial support.

Read at the 93rd Annual Meeting of The American Association for Thoracic Surgery, Minneapolis, Minnesota, May 4-8, 2013.

Received for publication Feb 27, 2013; revisions received May 14, 2013; accepted for publication June 27, 2013; available ahead of print Aug 15, 2013.

Address for reprints: Todd K. Rosengart, MD, Michael E. DeBakey Department of Surgery, Baylor College of Medicine, 1709 Dryden Rd, Ste 1500, Houston, TX 77030 (E-mail: todd.rosengart@bcm.edu).

$0022-5223 / \$ 36.00$

Copyright $(2013$ by The American Association for Thoracic Surgery

http://dx.doi.org/10.1016/j.jtcvs.2013.06.029
}

artery bypass grafting (CABG) surgery, and nearly $13 \%$ of $\mathrm{CABG}$ patients present for surgery while receiving clopidogrel or another adenosine diphosphate inhibitor. ${ }^{2,3}$ Patients who undergo $\mathrm{CABG}$ while receiving such antiplatelet therapy have been reported to be at an increased risk of bleeding, transfusion complications, reoperation for bleeding, and mortality. ${ }^{4-8}$ However, discontinuing antiplatelet therapy may increase patients' risk of ischemic events, including stent thrombosis. ${ }^{9,10}$ It is important to balance these risks when deciding whether clopidogrel should be discontinued for a given patient. $^{1,11-14}$

The "2012 ACCF/AHA focused update of the guideline for the management of patients with unstable angina/ non-ST-elevation myocardial infarction" recommends withdrawing clopidogrel at least 5 days before $\mathrm{CABG}{ }^{15}$ However, there is marked variability in patients' responses to clopidogrel therapy because of variations in patient genotype, as well as other factors. ${ }^{16-18}$ This considerable heterogeneity potentially makes it difficult to safely use such an arbitrary interval for discontinuing clopidogrel treatment before $\mathrm{CABG}$ without incurring excessive thrombotic or bleeding risks with premature versus excessively delayed discontinuation, respectively. 


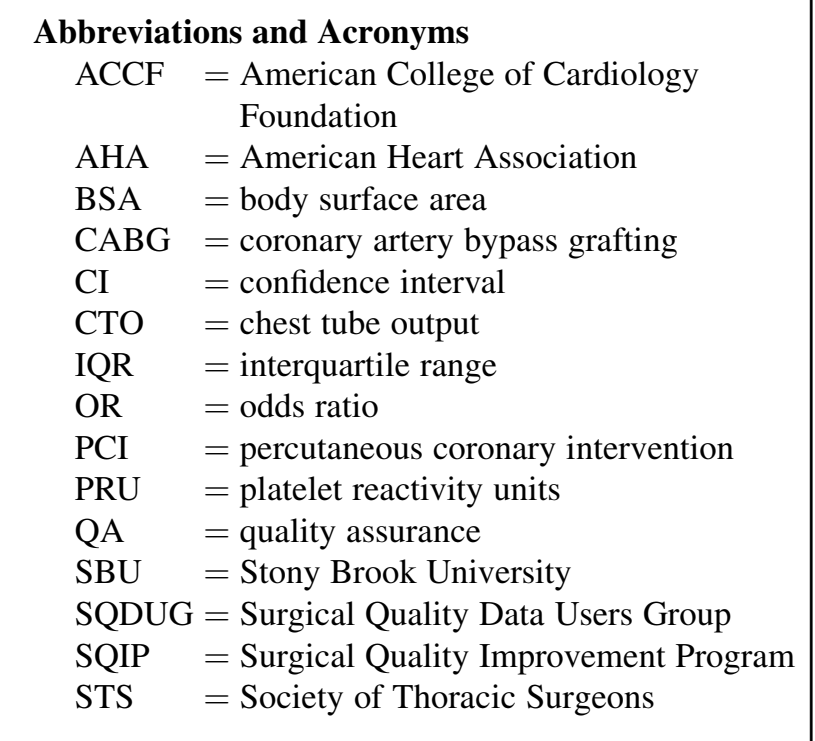

To implement these American College of Cardiology Foundation (ACCF)/American Heart Association (AHA) guidelines optimally, cardiac surgeons need to understand how their patients previously prescribed clopidogrel have responded to it. As part of the preoperative assessment of these patients, platelet functioning tests may be useful in identifying patients whose individual response to clopidogrel treatment puts them at highest risk of bleeding or thrombotic complications. Therefore, the purpose of this study was to identify preoperative "high-risk" cardiac surgery patients from preoperative platelet function testing.

\section{METHODS \\ Design}

As part of the Surgical Quality Improvement Program (SQIP) of the Stony Brook University (SBU) School of Medicine's Division of Cardiothoracic Surgery in the Department of Surgery, an expanded patient registry was designed and authorized by the SBU School of Medicine's Division of Medical and Regulatory Affairs. Under this program, SQIP routinely reported safety and outcomes data for all cardiac surgical patients to the Division of Cardiothoracic Surgery, Department of Surgery, and institutional quality assurance (QA) committees. The SQIP database comprised data from other QA program databases, including the New York State Cardiac Surgery Reporting System and the Society of Thoracic Surgeons (STS) National Adult Cardiac Surgery Database, as well as our cardiac surgery patient records. Moreover, for specific SBU QA projects, supplemental data were extracted from the medical records of surgical patients.

A Surgical Quality Data Users Group (SQDUG) secondarily reviewed and provided approval, as appropriate, of analyses of data extracts from patient records deidentified by the SQIP group, under the SQDUG protocol approved by the SBU School Institutional Review Board (Committee on Research in Human Subjects 170753-5). Under these protocols, this study was approved as a retrospective cohort study using deidentified records that had previously been gathered for QA reporting purposes.

\section{Study Population}

Deidentified records were extracted for all patients who underwent a "CABG-only" procedure at our institution from January 2010 to June $2011(\mathrm{n}=366)$. These patients underwent coronary bypass procedures either off-pump or with cardiopulmonary bypass and mild to moderate hypothermia according to our clinical standards, including the use of cell salvage. For this SQDUG-approved analysis, records were excluded for patients with an excessive risk of bleeding or transfusion, as established by STS guidelines ${ }^{14}$ including evidence of liver failure, dialysis, or renal dysfunction (creatinine $\geq 1.5 \mathrm{mg} / \mathrm{dL})(\mathrm{n}=38)$. Patients were also excluded for nonaspirin, nonclopidogrel glycoprotein IIb/IIIa inhibitor use $(\mathrm{n}=8)$ or clopidogrel use without $\mathrm{P} 2 \mathrm{Y}_{12}$ testing $(\mathrm{n}=18)$, or if their record was incomplete $(\mathrm{n}=26)$.

\section{Platelet Functional Monitoring}

Preoperative platelet function was assayed using fresh blood samples drawn within 24 hours of surgery by measuring $\mathrm{P}_{2} \mathrm{Y}_{12}$ receptor blockade with the VerifyNow system (Accumetrics, San Diego, Calif). Technical details have been described elsewhere. ${ }^{19}$ For this study, historically reported platelet inhibition levels were converted into the inversely correlated platelet reactivity unit (PRU) scale more recently proposed by the vendor (Appendix 1, available online). A platelet inhibition level of $20 \%$ or less, which was previously considered a negligible or "safe" level of platelet inhibition for patients undergoing coronary bypass surgery, ${ }^{20}$ was accordingly translated into a PRU threshold of 237 or more (with a receiver-operator characteristic area under the curve of 0.93 ).

\section{CABG-Related Bleeding Outcomes}

Chest tube output (within the first 12 hours postoperatively), intraoperative and postoperative transfusions (within the first 24 hours), bleedingrelated complications (eg, reoperation for bleeding), 30-day operative mortality, 30-day readmission, and prolonged postoperative length of stay (greater than the upper $95 \%$ confidence limit for the "no clopidogrel" control group) served as the main outcomes for this study. Because patients with no preoperative use of clopidogrel may be regarded as having a "normal" 12-hour chest tube output, this subset's upper limit threshold (95\% confidence interval $[\mathrm{CI}]$ ) was used as the cutoff value to dichotomize a chest tube output that was normal versus significantly higher than normal. In addition to the total units of allogeneic blood product transfused, transfusions were also coded dichotomously with regard to whether any amount of a given product—allogeneic red blood cells, platelets, or fresh frozen plasma - had been transfused intraoperatively or within 24 hours postoperatively. Finally, a composite outcome indicative of surgery-related bleeding events was defined as "high" chest tube output or coagulation product (platelet or fresh frozen plasma) transfusion.

\section{Statistical Analysis: Primary Hypothesis Testing}

To test our primary study hypothesis, we divided the patients into 2 groups according to their preoperative platelet function: higher PRU ( $\geq 237$; ie, the literature-based threshold for bleeding due to platelet dysfunction, equivalent to $0 \%-20 \%$ platelet inhibition) and lower PRU $(<237$; ie, the literature-based equivalent to platelet inhibition $>20 \%){ }^{20}$ Outcomes between these groups were compared by using $\chi^{2}$ and Fisher exact tests. Differences in demographics and preoperative medication use were adjusted for by multivariate logistic regression to determine whether the higher- and lower-PRU groups differed with regard to CABG bleedingrelated outcomes. A $95 \%$ CI was used. All calculations were performed with SAS, version 9.2, software (SAS Institute, Inc, Cary, NC).

\section{Exploratory Analyses}

For supplemental analyses, the PRU predictor variable was recategorized through histogram plotting (Figure 1). A threshold analysis was performed to identify PRU cutoffs to optimize differences between subgroup outcomes using the estimation approach described by Tobin. ${ }^{21}$ This analysis separated patients into 3 groups on the basis of platelet function: high-PRU (>290), intermediate-PRU (200-290), and low-PRU (<200). These 3 groups' outcomes were compared by using $\chi^{2}$, Fisher exact, and 


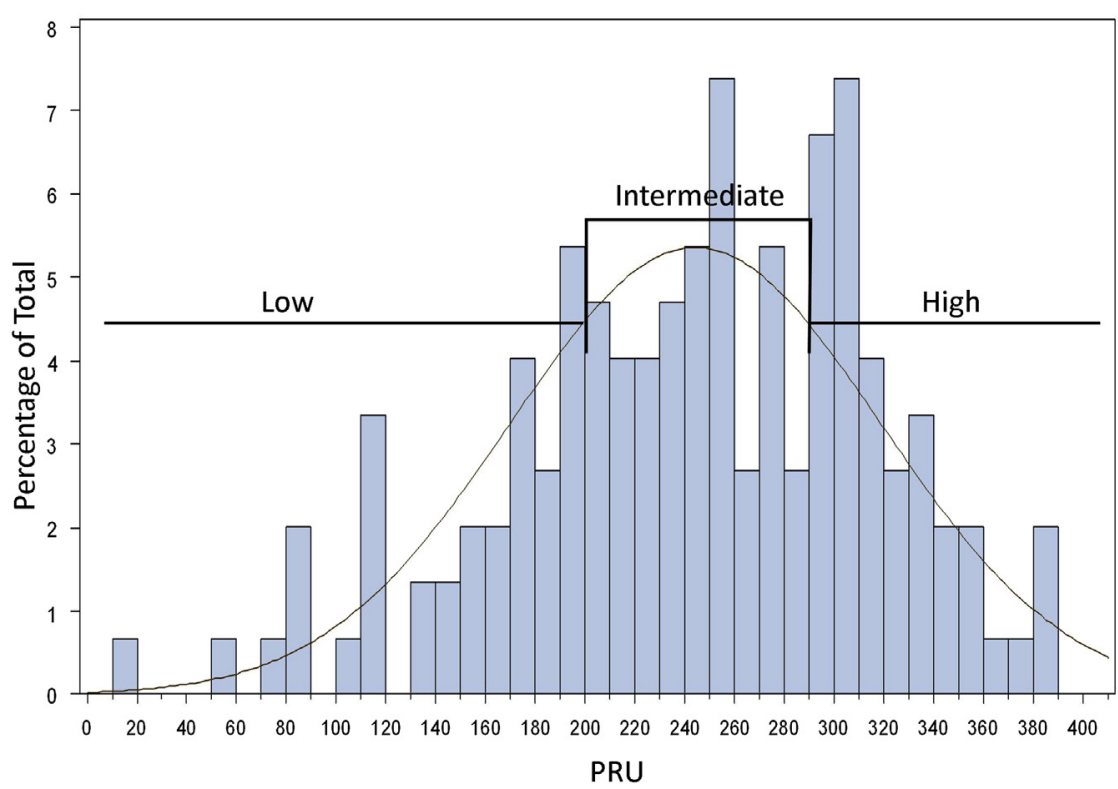

FIGURE 1. Platelet reactivity units ( $P R U s)$ as assayed by measuring $P 2 \mathrm{Y}_{12}$ receptor blockade within 24 hours of surgery for patients who received clopidogrel before coronary bypass surgery $(\mathrm{n}=149)$. This analysis separated the patients into 3 groups on the basis of platelet function: high PRU (>290), intermediate PRU (200-290), and low PRU (<200).

Wilcoxon rank-sum tests. As appropriate, other patient risk factors were included as covariates in a multivariate logistic regression.

\section{RESULTS}

\section{Patient Characteristics}

After excluding patients with risk factors for bleeding or transfusion (as previously noted), our final CABG cohort comprised 149 patients (54\% of total) who had received preoperative clopidogrel and 127 patients (46\% of total) who had not received clopidogrel preoperatively. The 149 patients who underwent CABG after clopidogrel administration were predominantly male $(81 \%)$, white $(91 \%)$, and non-Hispanic (95\%), with a median age of 65 years (interquartile range [IQR], 58-73 years) and a mean body surface area (BSA) of 2.0 (range, 1.9-2.2). Operation was defined as urgent in $145(97 \%)$ of cases (Table 1).

Regarding preoperative risk factors for bleeding or transfusion, $105(70 \%)$ of the patients had received aspirin, 13 $(9 \%)$ had a history of peripheral vascular disease, and $104(70 \%)$ had abnormally low hematocrit $(<42 \%)$. Offpump surgery was performed in 59 cases $(40 \%)$. The average number of distal bypasses was 3.4 (95\% CI, 3.23.5). Crossclamp and cardiopulmonary bypass times were 57 (95\% CI, 53-60) and 90 (95\% CI, 85-96) minutes, respectively. Epsilon amino-caproic acid was administered in $270(98 \%)$ of cases, whereas tranexamic acid was administered in no cases. No patient had evidence of sepsis/shock or a history of coagulopathy.

\section{Clinical Outcomes}

Overall, the 30-day operative mortality rate for our study cohort was $3 \%$ (Table 1 ). Three patients $(2 \%)$ required reoperation for bleeding, and 21 patients $(14 \%)$ were readmitted within 30 days of primary discharge. The median postoperative length of stay was 5 days (IQR, 4-6 days).

The number of patients transfused with any allogeneic blood products either intraoperatively or within 24 hours postoperatively was $85(57 \%): 33(22 \%)$ were transfused intraoperatively only, $19(13 \%)$ were transfused postoperatively only, and $33(22 \%)$ were transfused during both time intervals (Table 2). Of these patients, $63(43 \%)$ received an allogeneic red blood cell transfusion, $33(22 \%)$ received a fresh frozen plasma transfusion, and $57(38 \%)$ received a platelet transfusion.

The median 12-hour chest tube output was $350 \mathrm{~mL}$ (IQR, 260-490 mL). Based on the mean and 95\% CI for 12-hour chest tube output calculated for the no clopidogrel control group (mean, $398 \mathrm{~mL}$; 95\% CI, 359-437 mL), the dichotomous end point for high 12-hour chest tube output (defined as 12-hour chest tube output $>437 \mathrm{~mL}$ ) occurred in 62 patients $(42 \%)$ in the clopidogrel-treated group.

\section{Platelet Reactivity Groups}

Eighty-five $(57 \%)$ of the clopidogrel-treated patients were categorized as having higher platelet reactivity (PRU $\geq 237)$, and the remaining $64(43 \%)$ were classified as having lower platelet reactivity (PRU 0-236). There were no differences $(P>.1)$ between these 2 groups in nearly all bleeding/transfusion risk factors (including age, sex, BSA, urgent/emergent surgery, on/off-pump procedures, and preoperative use of aspirin), except that higher-PRU patients were more likely to have an abnormal hematocrit when they entered the operating room $(P=.04$, Table 3$)$. 
TABLE 1. Descriptive characteristics of the clopidogrel-treated CABG cohort

\begin{tabular}{|c|c|c|c|}
\hline $\begin{array}{c}\text { Descriptive } \\
\text { characteristics }\end{array}$ & All $(N=149)$ & $\begin{array}{c}\text { Higher PRU } \\
\text { (PRU, } \geq 237 \\
\quad \mathbf{n}=\mathbf{8 5})\end{array}$ & $\begin{array}{c}\text { Lower PRU } \\
\text { (PRU, 0-236; } \\
\text { n= 64) }\end{array}$ \\
\hline \multicolumn{4}{|l|}{ Sex } \\
\hline Female & $29(19)$ & $19(22)$ & $10(16)$ \\
\hline Male & $120(81)$ & $66(78)$ & $54(84)$ \\
\hline \multicolumn{4}{|l|}{ Race } \\
\hline White & $135(91)$ & $74(87)$ & $61(95)$ \\
\hline $\begin{array}{c}\text { Black/African } \\
\text { American }\end{array}$ & $3(2)$ & $3(4)$ & $0(0)$ \\
\hline Other & $11(7)$ & $8(9)$ & $3(45)$ \\
\hline \multicolumn{4}{|l|}{ Ethnicity } \\
\hline Hispanic & $7(5)$ & $3(4)$ & $4(6)$ \\
\hline Non-Hispanic & $141(95)$ & $82(96)$ & $59(92)$ \\
\hline \multicolumn{4}{|l|}{ Priority } \\
\hline Elective & $1(1)$ & $1(1)$ & $0(0)$ \\
\hline Emergent & $3(2)$ & $3(4)$ & $0(0)$ \\
\hline Urgent & $145(97)$ & $81(95)$ & $64(100)$ \\
\hline Age, y & $65(58-73)$ & $66(58-73)$ & $63.5(57-73)$ \\
\hline Body surface area, $\mathrm{m}^{2}$ & $2(1.9-2.2)$ & $2(1.9-2.2)$ & $2(1.9-2.2)$ \\
\hline Diabetes mellitus & $59(40)$ & $38(45)$ & $21(33)$ \\
\hline OR entry/exit time, min & $328(293-376)$ & $333(301-370)$ & $326(282-378)$ \\
\hline Reoperation for bleeding & $3(2)$ & $1(1)$ & $2(3)$ \\
\hline PLOS high & $36(24)$ & $22(26)$ & $14(22)$ \\
\hline Readmission (30 d) & $21(14)$ & $11(13)$ & $10(16)$ \\
\hline Mortality $(30 \mathrm{~d})$ & $4(3)$ & $1(1)$ & $3(5)$ \\
\hline
\end{tabular}

\section{Outcomes Analysis}

The incidence of transfusion of coagulation factors (ie, platelets or fresh frozen plasma) differed significantly between the PRU groups, as did the incidence of high chest tube output (Table 3). Univariate analysis showed that, compared with the higher-PRU group, the lower-PRU group was more likely to have a high chest tube output at 12 hours (odds ratio [OR], 1.99; 95\% CI, 1.02-3.88; $P=.04$; c-index, 0.584 ) and to have a coagulation factor transfusion
(OR, 2.33; 95\% CI, 1.2-4.54; $P=.01$; c-index, 0.603). The incidence of the composite outcome of high chest tube output or coagulation factor transfusion (OR, 2.46; $95 \% \mathrm{CI}, 1.22-4.95 ; P=.012)$ showed the highest predictability as a function of PRU group (c-index, 0.606).

Multivariate models were adjusted for the difference between groups in the prevalence of abnormal preoperative hematocrit - the only bleeding/transfusion risk factor that varied between groups-and the c-indices from all multivariate models indicated a better predictive fit than their univariate counterparts (Table 4). By multivariate analysis, the lower-PRU group was again more likely to have a coagulation factor transfusion (OR, 2.82; 95\% CI, 1.39-5.73; $P=.0004$; c-index, 0.642 ) and more likely to have the combination outcome of either high chest tube output or coagulation factor transfusion (OR, 2.35; 95\% CI, 1.15-4.8; $P=.02$; c-index, 0.635) than the higher-PRU group. However, multivariate analysis showed that chest tube output alone was not significantly different between the higher- and lower-PRU groups $(P=.09)$.

\section{Exploratory Analysis}

To explore the possibility of generating bleeding/transfusion outcomes data that more closely reflect the population of patients presenting for open heart surgery after clopidogrel treatment, cutoff points in the distribution of the PRU assay results (Figure 1) were used to define the 3 PRU comparison groups: high (PRU, $>290 ; \mathrm{n}=48$ ), intermediate (PRU, 200-290; $\mathrm{n}=61$ ), and low (PRU, <200; $\mathrm{n}=40$ ). Furthermore, because patients who had not received clopidogrel before CABG (the no-clopidogrel control group; $\mathrm{n}=127$ ) did not differ significantly from the high-PRU group in key risk factors and outcomes, these 2 groups were combined in this supplemental analysis $(\mathrm{n}=175)$.

There were no differences among the low-PRU, intermediate-PRU, and high-PRU/no-clopidogrel groups in nearly all bleeding and transfusion risk factors (including age, sex, BSA, urgent/emergent surgery, on/off-pump procedures, and preoperative hematocrit), except for preoperative use of aspirin, which was greater in the

TABLE 2. Perioperative transfusions for PRU groups

\begin{tabular}{|c|c|c|c|c|c|c|}
\hline \multirow[b]{2}{*}{ Transfusion characteristics } & \multicolumn{2}{|c|}{ All $(N=149)$} & \multicolumn{2}{|c|}{ Higher PRU (PRU, $\geq 237 ; \mathbf{n}=\mathbf{8 5})$} & \multicolumn{2}{|c|}{ Lower PRU (PRU, 0-236; $n=64)$} \\
\hline & No. $(\%)$ & Median (IQR)* & No. $(\%)$ & Median (IQR)* & No. $(\%)$ & Median (IQR)* \\
\hline Any transfusion & $85(57)$ & $3(2-6)$ & $48(57)$ & $3(2-5)$ & $37(58)$ & $4(2-6)$ \\
\hline Intraoperative only & $33(22)$ & $3(2-3)$ & $21(25)$ & $2(2-3)$ & $12(19)$ & $3(2-6.5)$ \\
\hline Postoperative (within $24 \mathrm{~h}$ ) only & $19(13)$ & $2(1-4)$ & $10(12)$ & $2(1-3)$ & $9(14)$ & $1(1-4)$ \\
\hline $\begin{array}{l}\text { Both intraoperative and } \\
\text { postoperative }\end{array}$ & $33(22)$ & $5(4-7)$ & $17(20)$ & $6(3-7)$ & $16(25)$ & $5(4-7.5)$ \\
\hline Red blood cell transfusion & $63(42)$ & $2(1-3)$ & $39(46)$ & $2(1-3)$ & $24(38)$ & $2(1.5-3)$ \\
\hline Platelet transfusion & $57(38)$ & $2(1-3)$ & $24(28)$ & $2(1-3)$ & $33(52)$ & $2(1-2)$ \\
\hline Fresh frozen plasma transfusion & $33(22)$ & $2(2-3)$ & $16(19)$ & $2(2-2.5)$ & $17(27)$ & $2(2-3)$ \\
\hline
\end{tabular}

$P R U$, Platelet reactivity unit; $I Q R$, interquartile range. *Median (IQR) is reported for individuals with a positive indication for that trait; those without the trait were not included in the calculation. 
TABLE 3. Analysis of risk factors and bleeding/transfusion outcomes for PRU groups

\begin{tabular}{|c|c|c|c|c|}
\hline Patient characteristics & All $(N=149)$ & $\begin{array}{c}\text { Higher PRU } \\
(\text { PRU, } \geq 237 ; \mathbf{n}=\mathbf{8 5})\end{array}$ & $\begin{array}{c}\text { Lower PRU } \\
(\text { PRU, 0-236; } \mathbf{n}=64)\end{array}$ & $\chi^{2} /$ Fisher $P$ value \\
\hline \multicolumn{5}{|l|}{ Demographics } \\
\hline Female sex & $29(19)$ & $19(22)$ & $10(16)$ & .305 \\
\hline \multicolumn{5}{|l|}{ Preoperative risk factors } \\
\hline Aspirin & $105(70)$ & $63(74)$ & $42(66)$ & .324 \\
\hline Peripheral vascular disease & $13(9)$ & $5(6)$ & $8(13)$ & .095 \\
\hline Abnormal (low) hematocrit* & $106(71)$ & $66(78)$ & $40(63)$ & .043 \\
\hline \multicolumn{5}{|l|}{ Operative risk factors } \\
\hline Off-pump procedure & $59(40)$ & $30(35)$ & $29(45)$ & .216 \\
\hline Composite clinical outcome $\dagger$ & $57(38)$ & $33(39)$ & $24(38)$ & .869 \\
\hline \multicolumn{5}{|l|}{ Bleeding/transfusion outcomes } \\
\hline Red blood cell transfusion & $63(42)$ & $39(46)$ & $24(38)$ & .305 \\
\hline Coagulation factor transfusion & $64(43)$ & $29(34)$ & $35(55)$ & .012 \\
\hline High chest tube output $\ddagger$ & $62(42)$ & $29(34)$ & $33(52)$ & .033 \\
\hline Bleeding/transfusion composite outcome $\S$ & $92(62)$ & $45(53)$ & $47(73)$ & 011 \\
\hline
\end{tabular}

intermediate-PRU group than in the other 2 groups (Table 5 ). There was likewise no difference between groups in clinical outcomes, including intensive care unit stay or time on ventilator, or the composite outcome of 30-day postoperative mortality, reoperation for bleeding, postoperative length of stay greater than 1 SD from mean, and readmission within 30 days of primary hospital discharge (Table 5).

When evaluated successively, univariate analysis showed that the odds of having high chest tube output or coagulation factor transfusion increased significantly as an incremental function of this supplemental PRU grouping (OR, 2.26; $P<.0001$; Table 4).

Multivariate models adjusted for preoperative use of aspirin all indicated a better predictive fit than their

TABLE 4. Univariate analysis of bleeding/transfusion outcomes as a function of exploratory PRU group

\begin{tabular}{lcccc}
\hline \multicolumn{1}{c}{ Bleeding outcomes } & Odds ratio & $\mathbf{9 5} \%$ CI & $\boldsymbol{P}$ value & c-index \\
\hline High chest tube output* & 1.71 & $1.22-2.38$ & .002 & 0.598 \\
High PRU/no clopidogrel & 1.0 & & & \\
Intermediate PRU & 1.83 & $1.0-3.33$ & .049 & \\
$\quad$ Low PRU & 2.81 & $1.40-5.67$ & .004 & \\
Coagulation factor & 2.03 & $1.45-2.85$ & $<.0001$ & 0.623 \\
$\quad$ transfusion & & & & \\
$\quad$ High PRU/no clopidogrel & 1.0 & & & \\
$\quad$ Intermediate PRU & 1.69 & $0.92-3.09$ & .09 & \\
$\quad$ Low PRU & 4.51 & $2.18-9.34$ & $<.0001$ & \\
High chest tube output or any & 2.26 & $1.56-3.26$ & $<.0001$ & 0.633 \\
$\quad$ coagulation factor & & & & \\
$\quad$ transfusion* & & & & \\
$\quad$ High PRU/no clopidogrel & 1.0 & & & \\
Intermediate PRU & 2.26 & $1.24-4.12$ & .008 & \\
$\quad$ Low PRU & 5.09 & $2.23-11.68$ & .0001 & \\
\hline
\end{tabular}

PRU, Platelet reactivity unit; $C I$, confidence interval. *High chest tube output: 12 -h output, greater than $437 \mathrm{~mL}$. univariate counterparts (Table E1); all outcomes were significantly different across the supplemental PRU groupings. By this analysis, the ORs compared with the high-PRU/no-clopidogrel (ie, reference) group were each incrementally greater in the intermediate- and low-PRU groups for high chest tube output (OR, 1.72; 95\% CI, $1.23-2.42 ; P=.002$; c-index, 0.625$)$ and for coagulation factor transfusion (OR, 2.08; 95\% CI, 1.47-2.94; $P<.0001$; c-index, 0.65). The ORs for high chest tube output were $2.08(95 \% \mathrm{CI}, 1.12-3.86 ; P=.02)$ and 2.73 (95\% CI, 1.34-5.57; $P=.006)$ for the intermediate- and low-PRU groups, respectively, versus the reference group, and the ORs for coagulation factor transfusion were 1.95 (95\% CI, 1.04-3.63; $P=.037$ ) and 4.46 (95\% CI, 2.139.33; $P<.0001)$, respectively. The OR for high chest tube output or coagulation factor transfusion as a composite index was also significantly higher in the intermediate-PRU (OR, 2.67; $P=.02$ ) and low-PRU (OR, 5.08; $P=.0002)$ groups than in the reference group (Table E1).

\section{DISCUSSION}

This study showed that the risks of bleeding and transfusion in patients who undergo $\mathrm{CABG}$ after clopidogrel administration can be predicted by a point-of-care platelet reactivity assay. These preliminary findings suggest specific platelet activity thresholds (represented by cut points in PRU, as measured by this assay) that could be used to predict a patient's risk of bleeding and transfusion complications. Thus, clinicians may be able to better manage the timing of CABG after clopidogrel cessation by using such point-of-care testing rather than adhering to arbitrary time intervals, such as those advocated by the ACCF/AHA guidelines. More specifically, our data indicate that using these platelet reactivity guidelines to determine the interval 
TABLE 5. Risk factors and outcomes for exploratory PRU groups

\begin{tabular}{|c|c|c|c|c|}
\hline Patient characteristics & $\begin{array}{c}\text { High } \\
(\text { PRU, }>\mathbf{2 9 0} ; \mathbf{n}=175)\end{array}$ & $\begin{array}{c}\text { Intermediate } \\
(\text { PRU, 200-290; } \mathbf{n}=6 \mathbf{6 1})\end{array}$ & $\begin{array}{c}\text { Low } \\
(\text { PRU, }<200 ; \mathbf{n}=\mathbf{4 0}) \\
\end{array}$ & $\chi^{2} /$ Fisher $P$ value \\
\hline \multicolumn{5}{|l|}{ Demographics } \\
\hline Female sex & $43(25)$ & $10(16)$ & $5(14)$ & .1447 \\
\hline \multicolumn{5}{|l|}{ Preoperative risk factors } \\
\hline Aspirin & $104(59)$ & $49(80)$ & $22(55)$ & .009 \\
\hline Peripheral vascular disease & $25(14)$ & $3(5)$ & $7(18)$ & .092 \\
\hline $\begin{array}{l}\text { Abnormal (low) hematocrit } \\
\text { in the OR* }\end{array}$ & $124(71)$ & $42(69)$ & $24(60)$ & .409 \\
\hline \multicolumn{5}{|l|}{ Operative risk factors } \\
\hline Off-pump procedure & $57(33)$ & $25(41)$ & $19(48)$ & .151 \\
\hline Composite clinical outcome $\dagger$ & $71(41)$ & $21(34)$ & $16(40)$ & .694 \\
\hline \multicolumn{5}{|l|}{$\begin{array}{l}\text { Bleeding/transfusion } \\
\text { outcomes }\end{array}$} \\
\hline Red blood cell transfusion & $67(38)$ & $22(36)$ & $17(43)$ & .808 \\
\hline $\begin{array}{l}\text { Coagulation factor } \\
\text { transfusion }\end{array}$ & $51(29)$ & $25(41)$ & $26(65)$ & $<.0001$ \\
\hline High chest tube output $\ddagger$ & $53(30)$ & $27(44)$ & $22(55)$ & .0057 \\
\hline $\begin{array}{l}\text { Bleeding/transfusion } \\
\text { composite outcome } \S\end{array}$ & $77(44)$ & $39(64)$ & $32(80)$ & $<.0001$ \\
\hline
\end{tabular}

PRU, Platelet reactivity unit; $O R$, operating room. *Abnormal hematocrit: male, $<42 \%$; female, $<37 \%$. $\dagger$ Composite clinical outcome: 30 -d postoperative mortality, reoperation for bleeding, prolonged postoperative length of stay ( $>95 \%$ confidence interval upper limit threshold for the no clopidogrel use group: $>6.17 \mathrm{~d}$ ), and readmission within $30 \mathrm{~d}$ of primary hospital discharge. $\ddagger$ High chest tube output: 12-h output, greater than $437 \mathrm{~mL}$. $\S$ High chest tube output or coagulation factor transfusion.

between clopidogrel discontinuation and CABG can prevent excessive thrombosis risk while also minimizing bleeding risk.

The increased risk of bleeding during and after CABG performed on patients who are receiving antiplatelet therapy, specifically clopidogrel, has been well established. ${ }^{4,5,9,10,22,23}$ More recently, the ability of clopidogrel to inhibit platelet activity by its blockade of the $\mathrm{P} 2 \mathrm{Y}_{12}$ platelet receptor has varied as a function of the expression of the relevant $C Y P 2 C 19 * 17$ and $C Y P 2 C 19 * 2$ and $* 3$ alleles governing the expression and activity of this receptor. $^{24}$ As a result of this heterogeneity in genetic expression, responses to clopidogrel treatment have varied widely across populations, and levels of platelet inhibition cannot, therefore, be predicted on the basis of clopidogrel dose or the length of the dosing-cessation interval. $6,11,16,18$ In this regard, the marked variability in patient response to clopidogrel therapy makes it challenging to identify those patients who are most at risk of excessive bleeding complications on the basis of their history of antiplatelet drug use. Point-of-care platelet functional testing before surgery, therefore, provides an objective measurement of platelet inhibition and a mechanism to predict antiplatelet agent-mediated bleeding risk.

The role of preoperative platelet function testing in predicting bleeding risk has been reviewed by Gurbel and colleagues. $^{25}$ They noted that Chen and colleagues ${ }^{22}$ were the first to show an association between platelet aggregation, as measured by light transmittance aggregometry, and CABGrelated bleeding in patients who underwent on-pump
CABG operations. In their report, of those patients with severe platelet dysfunction of less than $40 \%$ light transmittance, $92 \%$ received multiple transfusions. Kwak and colleagues $^{26}$ likewise found that patients who underwent off-pump CABG with platelet inhibition levels greater than $76 \%$ had increased chest tube output and higher transfusion requirements.

Compared with many of the assays used in these previous studies, the $\mathrm{P} 2 \mathrm{Y}_{12}$ assay used in the current study is rapid and readily deployed, with report times as brief as only a few hours, even as point-of-care testing. In addition, this assay is precise enough to allow clinicians to set clear PRU thresholds for predicting bleeding risk, as has been previously suggested. ${ }^{27}$ With this method, a $20 \%$ threshold for platelet inhibition has been used to guide the clinical management of bleeding occurrences, ${ }^{20}$ and another study identified a PRU of 189 as the threshold for increased bleeding risk in patients who undergo PCI. ${ }^{27}$

Unlike many prior CABG studies, our study was an institution-specific evaluation of a time-independent threshold for distinguishing between high- and normal-risk clopidogrel-treated patients. Furthermore, our exploratory analysis identified thresholds for high, intermediate, and nonsignificant risk compared with non-clopidogrel-treated patients, making it possible to balance bleeding risk against ischemic risk and urgency of operation. Using these PRUlevel thresholds enabled us to identify a high-risk group of patients with an $80 \%$ risk of high chest tube output or coagulation factor transfusion. We chose this composite end point because it incorporates 2 outcomes whose incidence 
in clopidogrel recipients is inversely related: "prophylactic" administration of coagulation factors and the incidence of high chest tube output. In consideration of this dual outcome, further delay of surgical intervention would appear to be clearly indicated in such a subpopulation.

\section{Study Limitations}

The current study has several limitations, including the potential for confounding that is inherent to this study's retrospective design, as well as the fact that transfusion triggers were not used in the management of the patients. Also, the possibility for preclinical bias exists; however, the prevalences of most known bleeding risk factors were similar among the study groups, and the study's outcomes were statistically significant even after multivariate adjustments for other bleeding-related risk factors. In addition, although precautions against bleeding and transfusion, including patient rewarming after bypass and the use of cell salvage, were taken as a matter of standard clinical practice at our institution, no standard algorithm was followed for managing bleeding in these patients. Despite these limitations, our transfusion rate of approximately $50 \%$ overall is similar to the $56 \%$ transfusion rate for CABG reported in the STS database, ${ }^{2}$ suggesting that the blood conservation practices used in this study were consistent with national norms.

\section{CONCLUSIONS}

Our findings support the use of separate cut points for platelet activity-assay results to identify CABG patients who are at high risk of bleeding and transfusion, specifically among patients who were previously receiving the antiplatelet agent clopidogrel. Additional studies are warranted to test whether these preliminary cut points could be used more broadly to support clinical decision making, such as choosing the best time interval between clopidogrel discontinuation and CABG to minimize bleeding and transfusion risk. Moreover, it will be important to determine whether using platelet activity assay thresholds yields better outcomes overall (with regard to bleeding, transfusion, major adverse cardiac events, and length of stay) than using current standards based on arbitrary time delay intervals.

\section{References}

1. Steinhubl SR, Berger PB, Mann JT III, Fry ET, DeLago A, Wilmer C, et al. Early and sustained dual oral antiplatelet therapy following percutaneous coronary intervention: a randomized controlled trial. JAMA. 2002;288:2411-20.

2. Bennett-Guerrero E, Zhao Y, O'Brien SM, Ferguson TB Jr, Peterson ED, Gammie JS, et al. Variation in use of blood transfusion in coronary artery bypass graft surgery. JAMA. 2010;304:1568-75.

3. Shahian DM, O'Brien SM, Filardo G, Ferraris VA, Haan CK, Rich JB, et al. The Society of Thoracic Surgeons 2008 cardiac surgery risk models: part 1-coronary artery bypass grafting surgery. Ann Thorac Surg. 2009;88:S2-22.

4. Berger JS, Frye CB, Harshaw Q, Edwards FH, Steinhubl SR, Becker RC. Impact of clopidogrel in patients with acute coronary syndromes requiring coronary artery bypass surgery: a multicenter analysis. J Am Coll Cardiol. 2008;52: 1693-701.
5. Ebrahimi R, Dyke C, Mehran R, Manoukian SV, Feit F, Cox DA, et al. Outcomes following pre-operative clopidogrel administration in patients with acute coronary syndromes undergoing coronary artery bypass surgery: the ACUITY (Acute Catheterization and Urgent Intervention Triage strategY) trial. J Am Coll Cardiol. 2009;53:1965-72.

6. Gurbel PA, Mahla E, Tantry US. Peri-operative platelet function testing: the potential for reducing ischaemic and bleeding risks. Thromb Haemost. 2011;106: 248-52.

7. Miceli A, Duggan SM, Aresu G, de Siena PM, Romeo F, Glauber M, et al. Combined clopidogrel and aspirin treatment up to surgery increases the risk of postoperative myocardial infarction, blood loss and reoperation for bleeding in patients undergoing coronary artery bypass grafting. Eur J Cardiothorac Surg. 2012;43:722-8.

8. Rao SV, O'Grady K, Pieper KS, Granger CB, Newby LK, Van de Werf F, et al. Impact of bleeding severity on clinical outcomes among patients with acute coronary syndromes. Am J Cardiol. 2005;96:1200-6.

9. Farzi S, Mahla E, Metzler H, Berghold A. The effect of preoperative treatment of $\mathrm{P} 2 \mathrm{Y} 12$ receptor antagonists on perioperative bleeding and mortality in patients treated with coronary artery bypass grafting (CABG). Cochrane Database Syst Rev. November 14, 2012. doi: 10.1002/14651858.CD010195.

10. Hamm CW, Bassand JP, Agewall S, Bax J, Boersma E, Bueno H, et al. ESC guidelines for the management of acute coronary syndromes in patients presenting without persistent ST-segment elevation: the task force for the management of acute coronary syndromes (ACS) in patients presenting without persistent STsegment elevation of the European Society of Cardiology (ESC). Eur Heart J. 2011;32:2999-3054.

11. Angiolillo DJ, Fernandez-Ortiz A, Bernardo E, Ramirez C, Sabate M, JimenezQuevedo P, et al. Clopidogrel withdrawal is associated with proinflammatory and prothrombotic effects in patients with diabetes and coronary artery disease. Diabetes. 2006;55:780-4.

12. Patrono C, Coller B, FitzGerald GA, Hirsh J, Roth G. Platelet-active drugs: the relationships among dose, effectiveness, and side effects: the Seventh ACCP Conference on Antithrombotic and Thrombolytic Therapy. Chest. 2004;126: 234S-64S

13. Pfisterer M, Brunner-La Rocca HP, Buser PT, Rickenbacher P, Hunziker P, Mueller $\mathrm{C}$, et al. Late clinical events after clopidogrel discontinuation may limit the benefit of drug-eluting stents: an observational study of drug-eluting versus bare-metal stents. J Am Coll Cardiol. 2006;48:2584-91.

14. Society of Thoracic Surgeons Blood Conservation Guideline Task Force Ferraris VA, Ferraris SP, Saha SP, Hessel EA II, Haan CK, et al. Perioperative blood transfusion and blood conservation in cardiac surgery: the Society of Thoracic Surgeons and The Society of Cardiovascular Anesthesiologists clinical practice guideline. Ann Thorac Surg. 2007;83:S27-86.

15. Jneid H, Anderson JL, Wright RS, Adams CD, Bridges CR, Casey DE Jr, et al. 2012 ACCF/AHA focused update of the guideline for the management of patients with unstable angina/non-ST-elevation myocardial infarction (updating the 2007 guideline and replacing the 2011 focused update): a report of the American College of Cardiology Foundation/American Heart Association Task Force on Practice Guidelines. J Am Coll Cardiol. 2012;60: 645-81.

16. Gurbel PA, Bliden KP, Hayes KM, Yoho JA, Herzog WR, Tantry US. The relation of dosing to clopidogrel responsiveness and the incidence of high post-treatmen platelet aggregation in patients undergoing coronary stenting. J Am Coll Cardiol. 2005;45:1392-6.

17. Jaremo P, Lindahl TL, Fransson SG, Richter A. Individual variations of platelet inhibition after loading doses of clopidogrel. J Intern Med. 2002;252:233-8.

18. Mobley JE, Bresee SJ, Wortham DC, Craft RM, Snider CC, Carroll RC. Frequency of nonresponse antiplatelet activity of clopidogrel during pretreatment for cardiac catheterization. Am J Cardiol. 2004;93:456-8.

19. Malinin A, Pokov A, Swaim L, Kotob M, Serebruany V. Validation of a VerifyNow-P2Y12 cartridge for monitoring platelet inhibition with clopidogrel. Methods Find Exp Clin Pharmacol. 2006;28:315-22.

20. Price MJ, Coleman JL, Steinhubl SR, Wong GB, Cannon CP, Teirstein PS. Onset and offset of platelet inhibition after high-dose clopidogrel loading and standard daily therapy measured by a point-of-care assay in healthy volunteers. Am J Cardiol. 2006;98:681-4.

21. Tobin J. Estimation of relationships for limited dependent variables. Econometr ica. 1958;26:24-36.

22. Chen L, Bracey AW, Radovancevic R, Cooper JR Jr, Collard CD, Vaughn WK, et al. Clopidogrel and bleeding in patients undergoing elective coronary artery bypass grafting. J Thorac Cardiovasc Surg. 2004;128:425-31. 
23. Herman CR, Buth KJ, Kent BA, Hirsch GM. Clopidogrel increases blood transfusion and hemorrhagic complications in patients undergoing cardiac surgery. Ann Thorac Surg. 2010;89:397-402.

24. Sibbing D, Koch W, Gebhard D, Schuster T, Braun S, Stegherr J, et al. Cytochrome 2C19*17 allelic variant, platelet aggregation, bleeding events, and stent thrombosis in clopidogrel-treated patients with coronary stent placement. $\mathrm{Circu}$ lation. 2010;121:512-8.

25. Gurbel PA, Bliden KP, Hiatt BL, O'Connor CM. Clopidogrel for coronary stenting: response variability, drug resistance, and the effect of pretreatment platelet reactivity. Circulation. 2003;107:2908-13.

26. Kwak YL, Kim JC, Choi YS, Yoo KJ, Song Y, Shim JK. Clopidogrel responsiveness regardless of the discontinuation date predicts increased blood loss and transfusion requirement after off-pump coronary artery bypass graft surgery. $J$ Am Coll Cardiol. 2010;56:1994-2002.

27. Patti G, Pasceri V, Vizzi V, Ricottini E, Di Sciascio G. Usefulness of platelet response to clopidogrel by point-of-care testing to predict bleeding outcomes in patients undergoing percutaneous coronary intervention (from the Antiplatelet Therapy for Reduction of Myocardial Damage During Angioplasty-Bleeding Study). Am J Cardiol. 2011;107:995-1000.

\section{Discussion}

Dr Song Wan (Sha Tin, Hong Kong). Thank you, Dr Rosengart, for this timely and important study and congratulations for this elegant presentation.

I have just a few short questions for you. The first question relates to the patient factor. Did all patients continue their aspirin before operation and through the operating day? If yes, your observation may not make $100 \%$ perfect sense unless you demonstrate that all the patients actually have the similar responsiveness to aspirin among all 3 groups.

And in the meantime, the recently published PARADOX study suggests a nonsmoker had reduced responsiveness to clopidogrel than smokers. So I just wondered, do you have the data about smoking status in all these patients, particularly the high function and the low function groups? Maybe I'd let you answer the first question.

Dr Rosengart. We did continue aspirin up to the time of use, which is part of nearly all guidelines in this regard. There is now apparent consensus that aspirin administration up to the time of surgery does not increase bleeding risks, but withdrawal in terms of ACS syndromes does increase the risk of stent thrombosis, so we continued ASA. We did correct for differences in ASA use amongst groups in our final analysis, however.

There are, as you point out, a number of causes of the variability of clopidogrel response, one being smoking; the most significant cause was genetic heterogeneity in terms of liver metabolism of the clopidogrel prodrug. This variability is, of course, accounted for in our analysis using PRU as our input variable.

Dr Wan. And the second question relates to the preoperative PRU measurement. Were those anesthetists and ICU staff actually aware of the result? If yes, do you confirm actually the decision for FFP and platelet transfusion was not biased by that result?

Dr Rosengart. Yes, that's an important question. This was retrospective, and in many cases, the surgeon, hopefully in all cases, the surgeon was aware of the PRU response. In our analysis, we consequently tried to capture a potential tradeoff between bleeding and platelet transfusion as a composite adverse outcome index-essentially, you pick your poison. Either you transfuse platelets to minimize the bleeding, or try to avoid the platelet transfusion, in which case you have a high chest tube output. This was the rationale for our looking at a chest tube output, platelet transfusion, in an either/or analysis. In fact, our findings support this as the outcome of operating on low PRU patients-they are either transfused or bleed, or in some cases both. What we found is that you are either giving prophylactic platelet transfusion, which in many cases was our practice, or looking at what the transfusion and bleeding rates were and then correcting post hoc.

Dr Wan. My last question relates to the treatment. Some studies suggested that tranexamic acid use could actually efficiently reduce the bleeding in clopidogreltreated patients. So did any patients in your study receive tranexamic acid? If yes, what about the duration intraoperatively and how many hours postoperatively?

Dr Rosengart. Nearly all $(98 \%)$ of our patients received Amicar. We do not use tranexamic acid.

Dr Wan. Thank you. And I thank the Association for the privilege of discussing this paper. Thank you. 
TABLE E1. Adjusted logistic regression analysis of outcomes as a function of exploratory PRU group*

\begin{tabular}{|c|c|c|c|c|}
\hline Bleeding outcomes & Odds ratio & $95 \%$ CI & $P$ value & c-index \\
\hline High chest tube output $\dagger$ & 1.72 & $1.23-2.42$ & .002 & 0.625 \\
\hline High PRU/no clopidogrel & 1.0 & & & \\
\hline Intermediate PRU & 2.08 & $1.12-3.86$ & .02 & \\
\hline Low PRU & 2.73 & $1.34-5.57$ & .006 & \\
\hline $\begin{array}{l}\text { Coagulation factor } \\
\text { transfusion }\end{array}$ & 2.08 & $1.47-2.94$ & $<.0001$ & 0.65 \\
\hline High PRU/no clopidogrel & 1.0 & & & \\
\hline Intermediate PRU & 1.95 & $1.04-3.63$ & .037 & \\
\hline Low PRU & 4.46 & $2.13-9.33$ & $<.0001$ & \\
\hline $\begin{array}{l}\text { High chest tube output or any } \\
\text { coagulation factor } \\
\text { transfusion } \dagger\end{array}$ & 2.36 & $1.61-3.47$ & $<.0001$ & 0.666 \\
\hline High PRU/no clopidogrel & 1.0 & & & \\
\hline Intermediate PRU & 2.67 & $1.43-4.97$ & .02 & \\
\hline Low PRU & 5.08 & $2.19-11.77$ & .0002 & \\
\hline
\end{tabular}

